\title{
Fission tracks and cooling rates of meteorites*
}

\author{
GHISLAINE CROZAZ \\ Department of Earth and Planetary Sciences and The McDonnel Center for \\ Space Sciences, Washington University, St. Louis, Missouri 63130, USA and \\ Physical Research Laboratory, Ahmedabad 380 009, India
}

\begin{abstract}
Recent work on fission track studies of meteorite samples to obtain cooling rates of meteorite parent bodies is reviewed. The cooling rates of chondrites are in excess of $1^{\circ} \mathrm{K} / 10^{\mathrm{B}}$ yr. Fission trick studies of phosphate grains in mesosiderites do not support the extremely slow cooling rates of $0.1^{\circ} \mathrm{K} / 10^{\circ} \mathrm{yr}$ for these meteorites, inferred from metallographic studies. The accumulating evidence from fission track studies indicates a gross underestimation of the cooling rates of meteorites as determined by the metallographic techniques.
\end{abstract}

Keywords. Fission tracks; chondrites; mesosiderites; metallography; cooling rates.

\section{Introduction}

Fission tracks have been used to gain insight into the thermal history of meteorites of various types. This history is related to the places and modes of origin of these objects. Meteorites are divided into three major groups: stony (less than $25 \% \mathrm{Fe}-\mathrm{Ni}$ ), stony-iron $(50 \% \mathrm{Fe}-\mathrm{Ni}, 50 \%$ silicate material), and iron (essentially made of $\mathrm{Fe}$ and $\mathrm{Ni}$ ) meteorites. The stony meteorites are further sub-divided into chondrites (containing rounded inclusions called chondrules) and achondrites (which contain no chondrule and most closely resemble terrestrial basalts). Stony-iron meteorites include pallasites (mainly olivine and $\mathrm{Fe}-\mathrm{Ni}$ ) and mesosiderites (which are complex breccias). The parent bodies from which the meteorites came were, in some cases, melted due to heat generated by radioactive heat sources within these bodies. Immiscible zones of pure metal liquid, pure silicate melt, and more complex mixtures of liquid metal and solid silicate minerals were formed during this melting event. Upon solidification, such zones served as the source of iron meteorites, achondrites and many of the stony-iron meteorites. Although the constituent chondrules were probably once molten, the chondrite themselves constitute a non-igneous assemblage of materials. Some chondrites have been heated severely enough to undergo various degrees of recrystallization. All these heating events are assumed to have occurred early in the history of the solar system, in bodies of asteroidal dimensions.

\section{Cooling rates of meteorites}

Cooling rates of meteorites were first inferred from their metal alloy compositions, and a large number of papers have been published on this subject; the results have been recently summarized by Wood (1979). From $900^{\circ} \mathrm{K}$ to $650^{\circ} \mathrm{K}$, two iron-nickel

\footnotetext{
* Paper presented at the second national seminar-cum-workshop on the use and application of solid state nuclear track detectors held at Physical Research Laboratory, Ahmedabad, India, during 24-26 February 1981.
} 
alloys (kamacite and taenite) are stable but their compositions and proportions vary with temperature and can be used to determine cooling rates. These are usually found to be of the order of $1-10^{\circ} \mathrm{K} / 10^{8} \mathrm{yr}$ with occasional values upto $1,000^{\circ} \mathrm{K} / 10^{6} \mathrm{yr}$. All types of meteorites have been studied in this manner. In the case of irons and pallasites, there is no independent way to measure cooling rates but, in the case of chondrites, achondrites, and mesosiderites, which all contain a U-rich phosphate phase, it is possible to use fission tracks to evaluate their thermal history. This is particularly important because there is an inconsistency between the metallographic results and the measured radiometric ages of the meteorites of all groups. This fact led Wood (1979) to suggest that metallographic cooling rates might be systematically underestimated by a factor of $\sim 6$.

\subsection{Cooling rates of chondrites}

Pellas and Storzer, in 1977, undertook a study of fission tracks in the U-rich minor phosphate phases (Whitlockite and chloroapatite) of chondrites. They also studied silicate gtains (feldspar, pyroxene and olivine) which are deficient in uranium, but contain tracks on their surfaces which were assumed to be produced when these grains were in contact with the U-rich phosplate grains. The phosphate abundance in chondrites is very low (less than $1 \%$ ) and thus the search for grains (from the major constituent phases of chondrites) which once were in contact with phosphate grains is both difficult and a lengthy process. A summary of this work has been recently reported by Pellas and Storzer (1981). Using the fission track densities they observed and the previously measured annealing properties for these various minerals, cooling rates in excess of $1^{\circ} \mathrm{K} / 10^{6}$ yr were inferred for the chondritic meteorites analysed

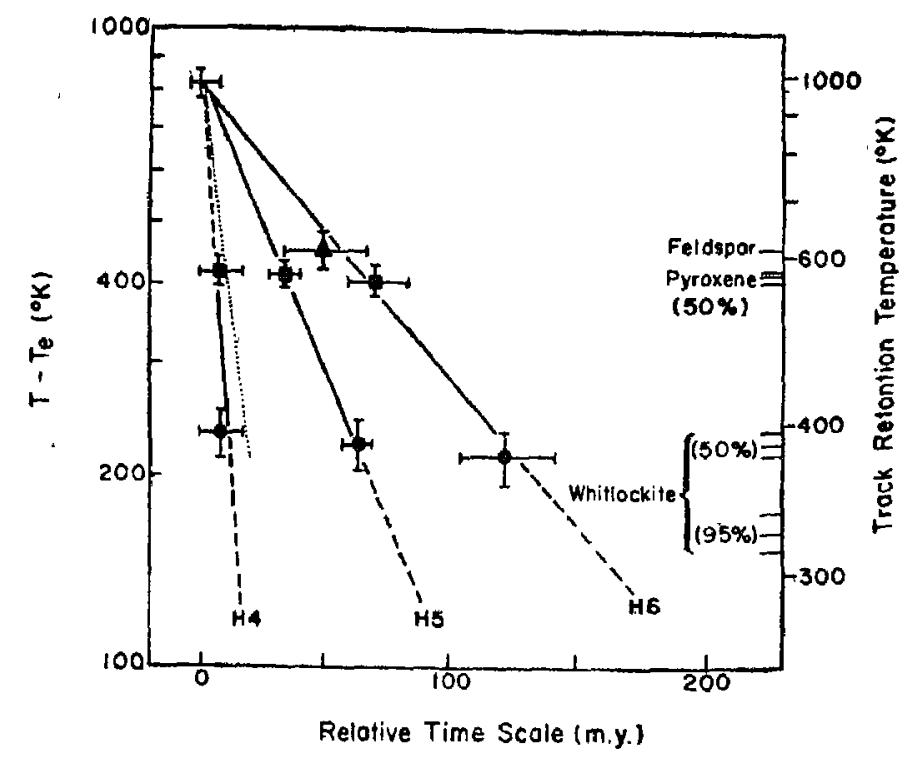

Figure 1. Cooling curves of $\mathrm{H}$ chondrites in the temperature interval 1000 to $375^{\circ} \mathrm{K}$. Solid lines follow experimental data, dotted lines are extrapolated values. The left ordinate is the temperature reduced by the surface temperature $T_{e}$ of the parent body of $\mathrm{H}$ chondrites. Assumed value of $T_{e}=160^{\circ} \mathrm{K}$. (Figure taken from Pellas and Storzer 1981). 
by them. For each subgroup of meteorites, the values seem to cluster pointing towards a common mode of origin. Figure 1 (taken from Pellas and Storzer 1981) shows the cooling curves determined for four different chondrites of the same group ( $\mathrm{H}$ group), but which differ in their degrees of metamorphism (lowest in $\mathrm{H} 4$ and highest in H6 chondrites). According to Pellas and Storzer (1981) the cooling rates are given by the slopes of the various experimental lines and are highest for the least metamorphosed chondrites ( $\mathrm{H} 4$ ) and lowest for the $\mathrm{H} 6$ chondrites, while the H5 chondrites seem to be intermediate. They conclude that these cooling rates are consistent with an onion-shell model for the parent bodies of these chondirtes (see figure 3) in which petrologic type 6 materials resided near the central region, and types 5,4 and 3 were located successively in the outer shells.

Scott and Rajan (1981) have recently published a combined metallographic and fission track study of four chondrites, including two so-called gas-rich chondrites, Weston and Fayetteville. The other two 'ordinary' chondrites analysed by them are Bhola and Mizo-Madaras. Gas-rich chondrites contain inclusions which were once, prior to the compaction of the meteorite, irradiated by the solar wind. They also contain crystals with solar flare tracks which were also acquired when these grains were residing at the very surface of an atmosphereless parent body prior to their incorporation into the meteorite.

The results obtained from metallographic studies of the Bhola chondrite is shown in figure 2, where the central nickel concentrations of taenite grains are plotted against the apparent distance from the edge of the grains for different types of materials sampled from this meteorite, within which these grains resided. All points plot coherently giving cooling rates of $0.1^{\circ} \mathrm{K} / \mathrm{m}$.y. in the temperature range 750 to $600^{\circ} \mathrm{K}$. The metallographic cooling rates thus seem to be underestimated by at least a factor of 5 , when compared to cooling rates obtained by fission track method (Pellas and

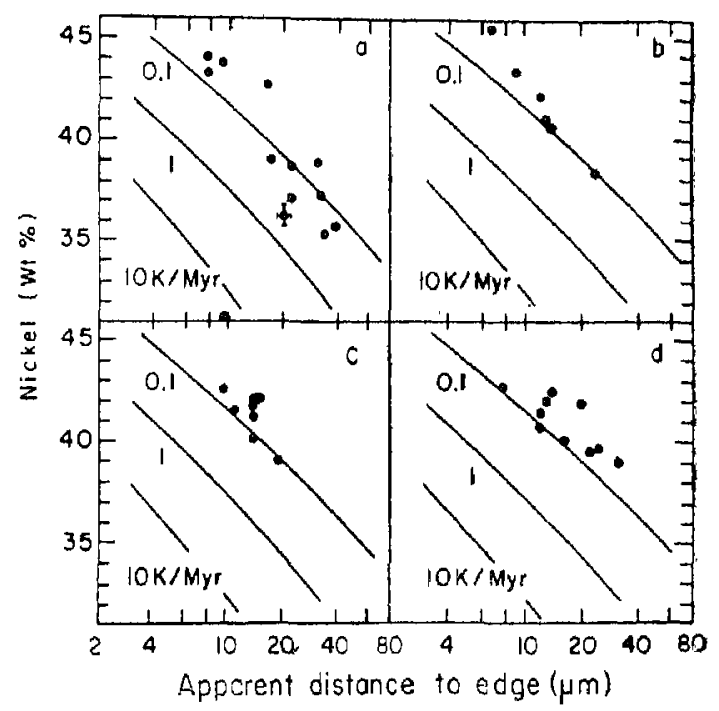

Figure 2. Central Ni concentrations and dimensions of taenite grains in host (a), shock-blackened (b), lightly shaded (c), and LL4 (d) xenoliths in Bhola. The data define a cooling rate of $0.1^{\circ} \mathrm{K} / \mathrm{m}$.y. The uniformity of the cooling rate in the host and the clasts suggests that this slow cooling occurred after the meteorite's compaction (Figure reproduced from Scott and Rajan 1981). 
Storzer 1981). The metallographic studies of the two gas-rich meteorites, on the other hand, showed that they include components which cooled at different rates (extremes differ by up to a factor of $\sim 100$ ), and thus in different environments, prior to the compaction of the meteorites. Although these data do not invalidate the onion-shell model proposed by Pellas and Storzer (1981), Scott and Rajan (1981) favour a model (see figure 3) in which maximum metamorphic temperatures were reached in planetesimals with a radius smaller than $10 \mathrm{~km}$ which were then accreted to form chondritic parent bodies. This is an interesting and new model which has not yet been fully tested.

\subsection{Cooling rates of mesosiderites}

Of all the meteorites for which metallographic cooling rates have been determined, the entire group of mesosiderites seems to have cooled extremely slowly. Powell (1969) suggested that mesosiderites might have cooled as slowly as $0 \cdot 1^{\circ} \mathrm{K} / 10^{6} \mathrm{yr}$. This cooling rate, if correct, has profound consequences as it implies that the mesosiderites must have evolved in a parent body appreciably larger than the largest asteroid currently observed.

We recently undertook (Crozaz and Tasker 1981) a fission track investigation of the U-rich whitlockites of mesosiderites with the objective of setting additional constraints on the thermal history of this group of meteorites. If the cooling rate of $0 \cdot 1^{\circ} \mathrm{K} / 10^{6} \mathrm{yr}$ is correct, the fission track ages of the whitlockites should be definitely lower than $3 \times 10^{9}$ years, the time by which the parent body of the mesosiderites will cool down to reach an effective track retention temperature.

We investigated eleven of the twenty one known mesosiderites including representatives of all the metamorphic groups. This study was complicated by the fact

\section{A. Onion shell model}

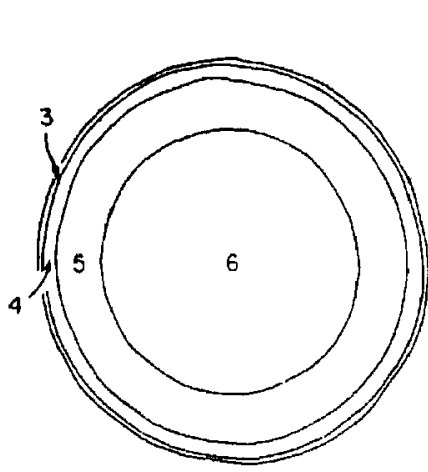

B. Metomorphosed-plonetesimal model

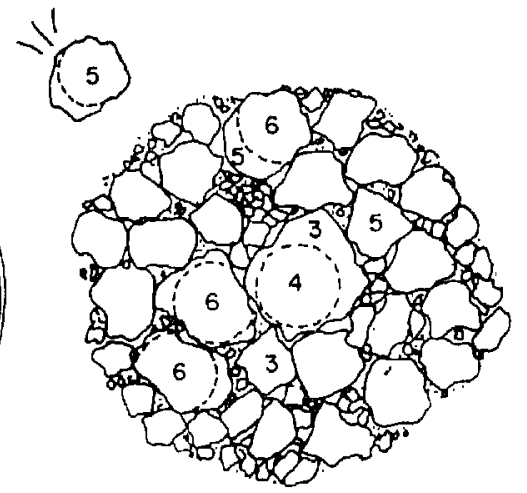

Figure 3. Schematic model for ordinary chondrite parent bodies. (A) Conventional onion-shell model in which radioactive heating after accretion produces a radial distribution of metamorphic types 3-6 (drawn to correspond the observed $H$ group fall frequencies). (B) Metamorphosed-planetesimal model in which maximum metamorphic temperatures are reached in small planetesimals $(\sim 10 \mathrm{~km}$ in radius $)$ before the chondritic parent body has accereted. Abundant mixing of types 3 to 6 in xenolithic chondrites (specially in LL chondrites) suggests that if (A) ever existed, it must hve been thoroughly mixed by subsequent collisions; (B) seems to fit the data better. (Figure reproduced from Scott and Rajan 1981). 
that meteoritic whitlockite can potentially register tracks from the following sources: (i) the spontaneous fission of ${ }^{288} \mathrm{U}$, (ii) the spontaneous fission of ${ }^{24} \mathrm{Pu}$, (iii) heavy particles in the cosmic rays, (iv) induced fission of $U$ and $T h$, and (v) nucler reactions induced mainly by high energy protons (short spallation recoil tracks). Various techniques were used to identify tracks from these sources, and to determine a fission track-age. Cosmic ray track densities were measured in adjacent U-poor giains, the uranium concentration in whitlockite was determined after neutron irradiation, and all track measurements were made using replicas studied in a scanning electron microscope. Our criteria were very conservative leading to lower limits for the actual fission track densities. Table 1 (from Crozaz and Tasker 1981) compares the measured fission track densities (column 2) in the whitlockite of mesosiderites of various metamorphic groups with the fission track densities expected from the decay of ${ }^{238} \mathrm{U}$ alone over a time period of $4.5 \times 10^{9} \mathrm{yr}$. Some mesosiderites have large excesses of fission tracks (presumably due to the decay of ${ }^{224} \mathrm{Pu}$ ); others have more modest excesses, whereas some do not have track excesses but still have apparent fission track ages, older than $3 \times 10^{9} \mathrm{yr}$. Based on these new results it appears that the previously inferred low cooling rates determined by metallographic techniques were much too low. With the lifting of the requirement of extremely low cooling rates, a number of asteroids with radii equal or less than $150 \mathrm{~km}$, which are concentrated in the inner portion of the asteroid belt and which have spectral reflectance characteristics compatible with the mesosiderite mineralogy (Gaffey and McCord 1977), are possible parent bodies for this group of meteorites.

Table 1. Fission tracks in the whitlockite of mesosiderite (Crozaz and Tasker, 1981)

\begin{tabular}{lcc}
\hline & $\begin{array}{c}\text { Measured } \\
\text { fission track } \\
\text { density }\left(\mathrm{cm}^{-3}\right)\end{array}$ & $\begin{array}{c}\text { Expected fission track } \\
\text { density }\left(\mathrm{cm}^{-3}\right)^{4}\end{array}$ \\
\hline Group 1 & $2 \times 10^{8}$ & $1.6 \times 10^{4}$ \\
Crab Orchard & $4 \times 10^{8}$ & $3.0 \times 10^{6}$ \\
Mount Padbury & $2 \times 10^{7}$ & $2.2 \times 10^{6}$ \\
Patwar & $10^{7}$ & $2.8 \times 10^{8}$ \\
Vaca Muerta & $2 \times 10^{5}$ & $5.4 \times 10^{8}-1 \times 10^{7}$ \\
Group 2 & & $1.6 \times 10^{8}$ \\
Veramin & $1.4 \times 10^{4}$ & $4.5 \times 10^{8}$ \\
Group 3 & $2.6 \times 10^{8}$ & $8.0 \times 10^{5}$ \\
Emery & $1.8 \times 10^{4}$ & \\
Estherville & & $1.7 \times 10^{8}$ \\
Morristown & $4.3 \times 10^{8}$ & \\
Group 4 & $4.9 \times 10^{8}$ & $10^{8}$ \\
Hainholz & & \\
Pinnaroo & & \\
\hline
\end{tabular}

*Calculated from the measured $U$ concentration and for a meteorite's age of $4.5 \times 10^{\prime}$ years. 
The accumulating evidence from fission track studies thus points towards a gross underestimation of the cooling rates of meteorites as determined by the metallographic techniques.

\section{References}

Crozaz G and Tasker D R 1981 Geochim. Cosmochim. Acta. (in press)

Gaffey M J and McCord T B 1977 Proc. Lunar Sci. Conf. 8th (New York: Pergamon Press), p. 113

Pellas P and Storzer D 1977 in Contets, asteroids, meteorites (ed.) A H Delsemme (Tuledo, Ohio: Univ. of Toledo Press) p. 355

Pellas P and Storzer D 1981 Philos. Trans. R. Soc. London Ser. A347 253

Powell B N 1969 Geochim. Cosmochim. Acta. 33789

Scott E R D and Rajan R S 1981 Geochim. Cosmochim. Acta 4553

Wood J A 1979 in Asteroids (ed.) T Gehrels (Tucson: Univ. Arizona Press) p. 849 